\title{
A EXPERIÊNCIA ESCOLAR E A SOCIALIZAC̣ÃO PRÉ-PROFISSIONAL DE PROFESSORES DE EDUCAÇÃO FÍSICA
}

\author{
José Ângelo Gariglio" \\ Universidade Federal de Minas Gerais (UFMG)
}

RESUMO: O presente artigo apresenta os resultados de uma pesquisa de caráter biográfico com dois professores de Educação Física. O estudo teve como objetivo central analisar as repercussões de experiências pré-profissionais vividas como estudantes da educação básica desses professores no desenvolvimento de modelos de ação profissional como professores de Educação Física no interior da escola. Buscamos identificar em que medida esse tempo e ambiente de socialização primária (família, ambiente da vida, educação no sentido lato) participaram ou participam do processo de constituição de crenças e certezas sobre o ensino e a docência em Educação Física na escola. O estudo aponta que essa experiência de préprofissional tem impactos nas percepções que os professores têm acerca do papel da Educação Física no currículo escolar e de um estilo de ensino que seria próprio do professor de Educação Física.

Palauras-chave: Educação Física. Formação de professores. Socialização profissional.

\footnotetext{
http://dx.doi.org/10.1590/0102-4698134352

* Doutor em Educação pela Pontifícia Universidade Católica do Rio de Janeiro (PUC-Rio). Professor Adjunto da Escola de Educação Física, Fisioterapia e Terapia Ocupacional (UFMG). Membro Permanente do Programa de Pós-Graduação em Educação da Universidade Federal de Minas Gerais (UFMG). Líder do Grupo de Pesquisa em Educação Física Escolar (ProEFE). Email: angelogariglio@hotmail.com
} 


\title{
THE SCHOOL EXPERIENCE AND THE PRE-PROFESSIONAL SOCIALIZATION OF TEACHERS OF PHYSICAL EDUCATION
}

\begin{abstract}
This article presents the results of a survey of biographical character with two Physical Education teachers. The study aimed mainly at the analysis of the impact of pre-professional experiences that these teachers experienced as students of basic education and their influence in developing models of professional action as Physical Education teachers within the school. We seek to identify the extent that time and environment of primary socialization (family, living environment, education in the broadest sense) participated or participate in the development of beliefs and certainties about teaching and teaching in physical education in the school. The study points out that the experience of pre-professional has impacts on the perceptions that teachers have about the role of physical education in the school curriculum and a teaching style proper of the physical education teacher.
\end{abstract}

Keywords: Physical Education. Teacher Education. Professional Socialization.

\section{A ORIGEM DO PROBLEMA DE PESQUISA}

Este texto relata os resultados de uma pesquisa ${ }^{1}$ feita com dois professores de Educação Física (EF) de uma escola profissionalizante. ${ }^{2}$ Interessou-nos investigar o prestígio das experiências formadoras vividas pelos sujeitos da pesquisa em tempos e espaços de aprendizagem pré-profissionais, ${ }^{3}$ mais especificamente, daquelas experiências formadoras vividas durante a trajetória como alunos da educação básica. Tentamos identificar em que medida esses tempos e ambientes de formação escolar repercutem sobre o processo de constituição de crenças e certezas sobre o ensino da Educação Física, constituindose em modelos de ação profissional ${ }^{4}$ orientadores da intervenção profissional desses docentes na escola. Pareceu-nos instigante indagar o que dessas experiências formadoras sobreviveu ao tempo e se constituiu em referência orientadora para a ação docente nesse universo pedagógico situado.

Ao tratarmos do tema sobre a existência de uma cultura docente específica dos professores de Educação Física, partimos do princípio de que o conjunto dos saberes pedagógicos obtidos por esses docentes não deve ser tratado apenas por meio de análises centradas na sua atividade profissional dentro da escola ou em sua formação inicial. Há que se considerar que os docentes podem mobilizar conhecimentos e formas de saber-fazer adquiridas em fontes, lugares e momentos diferenciados. A produção de análises sobre a trajetória das experiências vividas pelos professores de 
EF, em tempos e espaços de aprendizagem anteriores à inserção profissional, pode ser de suma importância para melhor compreensão dos modelos de ação profissional edificados pelos professores de EF. Mais do que isso, pode ajudar no acesso de vivências da experiência pré-profissional que influenciam a estruturação e a relação dos professores com a escola e com o ensino.

\section{OS ESTUDOS BIOGRÁFICOS E A HISTÓRIA DE VIDA DOS PROFESSORES}

Os estudos biográficos que tratam da história de vida dos professores representam uma ruptura com o paradigma processoproduto que vê o professor apenas como um técnico ou um perito dotado de um conjunto de competências e capacidade técnica necessárias ao desenvolvimento racional da ação pedagógica. Ao contrário dessa visão, a perspectiva colocada pelos estudos biográficos entende que a transformação produtiva dos saberes e das práticas de formação deve necessariamente incluir processos de reflexão e autoconhecimento que reconstituem os itinerários individuais de desenvolvimento (CATANI, 1998).

Essa visão biográfica coloca em relevo o fato de que há muitos fatores que influenciam o modo de pensar, sentir e atuar dos professores, ao longo do processo de ensino, a ver: o que são como pessoas, os seus diferentes contextos biográficos e experienciais e os contextos sociais onde crescem, aprendem e ensinam. Nessa perspectiva, é praticamente impossível separar o eu pessoal do eu profissional. Somos docentes; não apenas exercemos a função docente. O professor é uma pessoa e uma parte importante da pessoa. Ser professora e professor faz parte de nossa vida. É o outro em nós (NÓVOA, 1995; ARROYO, 2000).

Nesse horizonte de reflexão, ter acesso ao modo como cada pessoa se forma é ter em conta a singularidade da sua história e, sobretudo, a maneira singular como age, reage e interage com os seus contextos (HOLLY, 1995). Um percurso de vida é assim um percurso de formação, no sentido em que é um processo de formação (MOITA, 1995). Quais as conexões existentes entre essas histórias de formação e as práticas que escolhem para dar respostas ao "como fazer" do seu trabalho? Questões dessa natureza podem e devem se multiplicar caso se queira compreender as especificidades do ofício.

Ainda sobre esse tema, Goodson (1995) defende a tese de que é necessário se ter compreensão mais alargada da totalidade da vida do professor, de sua história de vida e de suas prioridades. 
O autor coloca em xeque a visão corrente de que, para melhorar a prática docente, se deva inicial e imediatamente incidir sobre essa prática. Para ele, devemos desmistificar a perspectiva que vê o professor apenas como um reflexo da sua prática. Nesta linha, compreende que as experiências de vida e o ambiente sociocultural são ingredientes-chave da pessoa que somos, do nosso sentido do eu e que o estilo de vida do professor dentro e fora da escola, sua identidade e sua cultura oculta têm impacto sobre os modelos de ensino e a prática educativa.

Os estudos sobre a história de vida dos professores trazem elementos importantes ao avanço da reflexão sobre as singularidades do ofício docente. Essa perspectiva teórico-metodológica enfatiza a visão de que os saberes da base da profissão são provenientes de várias fontes: da história de vida individual, da relação com a sociedade, da instituição escolar, de outros atores educativos da escola, dos lugares de formação e de experiências culturais de variada latitude.

No caso específico da nossa pesquisa, pareceu-nos importante investigar qual o peso da experiência pregressa com a instituição escolar - especialmente a trajetória como alunos da educação básica - para a compreensão da natureza dos saberes docentes que serão mobilizados e utilizados no próprio exercício do magistério. Isso porque algumas investigações relativas à história de vida de professores têm mostrado que uma parte do que eles sabem sobre o ensino provém da própria socialização como alunos da educação básica. Estudos recentes no campo da Educação Física (EF) têm mostrado ${ }^{5}$, por exemplo, que muitos alunos dos cursos de graduação já possuem intensa inserção dentro do universo dos conteúdos da EF (majoritariamente com o esporte), seja por terem sido atletas durante a infância e a adolescência, seja por já terem trabalhado como instrutores técnicos de determinadas modalidades esportivas, de dança ou de ginástica, seja pelas experiências significativas com as práticas corporais no tempo de lazer ou mesmo em equipes esportivas constituídas nas escolas. Tal experiência é de tal forma significativa que, além de ser crucial para a escolha da profissão, acaba por se constituir num espaço produtor de referências profissionais que são reutilizadas, de maneira não reflexiva, como conjunto de certezas que orientam desejos, escolhas ou prioridades na relação com os saberes da formação inicial.

Essa imersão se expressa em uma bagagem de conhecimentos anteriores, de crenças, de representações e de certezas sobre a prática docente que permanece forte e estável através do tempo. ${ }^{6}$ Tal experiência pré-profissional (escolar) tem influência significativa na compreensão da natureza dos sabres profissionais, do saber-fazer 
e do saber-ser, que são mobilizados e utilizados no próprio exercício do magistério (RAYMOND et al., 1993; RAYMOND, 2000; TARDIF; RAYMOND, 2000; TARDIF, 2002).

Tentamos identificar em que medida esses tempos e ambientes de formação participaram ou participam do processo de constituição de crenças e certezas sobre o ensino da Educação Física e o oficio docente nessa disciplina escolar. Parece-nos instigante perguntar o que dessas experiências formadoras sobreviveu ao tempo e se constituiu em referência orientadora do que seria a ação docente nesse universo pedagógico situado. O que da experiência de vida desses professores, ocorrida em tempos e ambientes formativos anteriores ao exercício profissional, pereniza e informa os nossos depoentes sobre os rumos específicos de sua prática docente na escola?

\section{A TRAJETÓRIA METODOLÓGICA}

As pesquisas de histórias de vida de professores, construídas em diferentes espaços e níveis de atuação da carreira, não visam investigar somente a vida de indivíduos particulares, mas principalmente as singularidades que referenciam também uma cultura profissional coletiva: a categoria dos profissionais docentes (OLIVEIRA, 2006). No caso específico desta pesquisa, a dos professores de Educação Física.

O uso do método biográfico permitiu-nos estreitar os laços, às vezes tênues, com o campo acadêmico, entre teoria e prática. $\mathrm{O}$ ato de dar a palavra aos professores, a partir dos sentidos construídos no presente, significou propiciar condições para que os indivíduos pesquisados reconstruíssem a própria história profissional. Para isso, priorizamos a entrevista narrativa, com o uso de relatos orais, pois acreditamos que os registros traduzidos na oralidade pelo trabalho da memória tragam à tona os processos formativos significativos e as aprendizagens neles construídos, bem como os movimentos identitários - as identidades transformadas pelas experiências vividas em tempos/espaços como profissional. A narrativa de si nos ajudou a adentrar em territórios existenciais, em representações, em significados construídos sobre a docência em Educação Física e sobre as aprendizagens elaboradas com base na experiência como estudante da educação básica. Ela ajudou a inserir o professor num processo de investigação/reflexão sobre os seus registros (OLIVEIRA, 2006).

Para o desenvolvimento da pesquisa, elegemos dois professores de Educação Física experientes, com o intuito de verificar 
em seus relatos contornos de alguns conhecimentos, do saber-fazer e do saber-ser, que são mobilizados e utilizados no próprio exercício do magistério, mesmo depois de uma longa e larga experiência com o ensino dessa disciplina escolar. ${ }^{7}$ Levamos em consideração aqui a classificação desenvolvida por Huberman (1992) sobre os ciclos de vida profissional de professores. Como nosso objeto de estudo centra seu foco de análise no peso da socialização pré-profissional na constituição de saberes docentes por professores/atores racionais, capazes de justificar sua própria racionalidade e os juízos que regem o seu fazer docente, entendemos que seria mais apropriado desenvolver a pesquisa com professores mais experientes e pretensamente mais maduros. Nessa direção, os nossos sujeitos estão enquadrados dentro da fase do ciclo profissional que Huberman (1992) denomina de "fase de diversificação". Segundo o autor, nessa fase os professores se lançariam a uma série de experiências profissionais, diversificando o material didático, o modo de avaliação, a forma de agrupar os alunos e as sequências do programa.

O primeiro sujeito da pesquisa é o prof. Mauro, profissional experiente, graduado em Educação Física pela Universidade Federal de Viçosa - MG, há 12 anos, com especialização em Educação Física escolar e com 16 anos no ensino dessa disciplina escolar. No período da realização do estudo, o nosso sujeito de pesquisa atuava numa escola profissionalizante da rede federal de ensino.

O segundo docente participante é o professor Leandro, de 42 anos, graduado em Educação Física pela Faculdade de Educação Física de Volta Redonda - RJ, com especialização em Ciência do Futebol. Tem 22 anos de experiência com o ensino dessa disciplina e trabalha na referida escola profissionalizante há mais de 12 anos. Ministrou aulas de EF em escolas de ensino fundamental e médio no Estado de Rondônia, além de ter adquirido experiência na Diretoria de Esportes e Lazer da Secretaria Municipal de Educação de Ariquemes, nesse mesmo Estado ${ }^{8}$.

É importante lembrar que a recordação do que já se viveu foi tratada mais como uma reinterpretação do que como uma reprodução do passado. Os professores, ao entrarem no trabalho de recontar a sua história pessoal, buscaram dar ordem e sentido ao passado em função do que vivem no presente. Melhor dizendo, foram as questões da prática profissional que ajudaram a selecionar os fatos mais significativos da história de sua relação com o universo da docência (HUBERMAN, 1995; FONTOURA, 1995). 
APRENDENDO A SER PROFESSOR DE EF: A SOCIALIZAÇÃO PRÉ-PROFISSIONAL EM QUESTÃO

Apoiados no entendimento de que parte das representações construídas pelos professores é apreendida no tempo e na interação com o universo de trabalho e que acaba se constituindo em rotinas, regras e valores sobre a profissão docente, buscamos compreender até que ponto as experiências anteriores à formação profissional, em especial aquela vivida durante a experiência como estudante na educação básica, tornam-se referentes significativos parar que esses docentes possam organizar e a operar a sua intervenção prática dentro do estabelecimento de ensino.

Inicialmente, ao pedirmos aos nossos professores que indicassem e reinterpretassem os fatos mais significativos de sua trajetória escolar como alunos da educação básica, esses ressaltaram ser a escola um local onde as práticas de ensino eram, majoritariamente, muito duras, sem muito sentido e com poucos momentos de prazer. Para os nossos sujeitos de pesquisa, as lembranças mais significativas da experiência escolar ocorreram fora da sala de aula, em tempos e espaços de aprendizagens informais, seja com os outros colegas, seja com os próprios professores. Nessa tentativa de reconstrução do passado, os nossos informantes focam sua atenção para os momentos ricos de conteúdo relacional, emocional e afetivo. Vejamos os relatos:

Eu me lembro de todos os professores, de situacõos que parece que aconteceram comigo ontem, e a que mais me marcou nessa trajetória foi um coral que a gente fer, eu participava de tudo, até Papai Noel de rua en já fui, teatro eu vou, sempre en fui tudo, de $1^{a}$ a $4^{a}$ série, tudo. $\mathrm{Na} 4^{a}$ série, participei do coral e sempre fui um desentoado, não sabia cantar, e a gente cantou uma música do Roberto Carlos, aquela 'está chegando a bora de dizer adeus', e todos os professores nós convidamos, e foi marcante pra caramba. Até hoje os professores ainda falam sobre isso. De $5^{a}$ a $8^{a}$ série foi a oportunidade maior ainda em termos de esporte, foram convites para fazer parte de equipes de outras escolas, convite para sair da escola. (Prof. Mauro)

A experiência mais marcante na escola foi quando apresentei uma peça de teatro, eu não me lembro o nome da peça, mas só sei que eu fiz. o papel de um mordomo, na época eu me lembro, en tive de anunciar para o Conde de Assumar alguém que estava chegando ao palácio, uma coisa assim. Então isso me marcou muito, se eu forçar um pouquinho aqui vem à memória minha fala, eu acho bacana, porque é a primeira experiência que eu tive de subir no palco e ver o mundo de outra maneira, é o pessoal sentado lá e eu em cima assim. Então, foi uma coisa marcante. (Prof. Leandro)

Vemos aqui que, ao selecionarem essas lembranças, os nossos docentes chamam a atenção para a existência de uma escola dentro de outra escola, onde perfilam aprendizagens tão significativas para a formação humana como aquelas engendradas dentro da sala de aula. 
São momentos e vivências educativas que permanecem ocultos e são tratados, na maioria das vezes, como algo menor e sem importância. Melhor dizendo: são vivências culturais - cultura entendida aqui no seu sentido mais amplo -, seja nos interstícios da vida institucional, seja em atividades festivas organizadas pela escola, que dão a ela a possibilidade de ser considerada como um local prazeroso e agradável.

A seleção desses momentos pelos professores parece-nos mostrar que essas atividades e vivências de cultura, no seu sentido amplo, apesar de minoritárias no quadro temporal da escola, são experiências educativas (afetivas, relacionais, sensíveis), vistas como as mais significativas dentro de um quadro hierárquico, interno, construído pelos próprios professores. Ao enfatizarem os momentos de alegria, gratuidade, convívio "pacífico" e afetivo com os professores, os nossos informantes parecem demonstrar mais sensibilidade para dimensões educativas presentes na vida escolar, que seriam consideradas como centrais no exercício de suas atividades profissionais na escola com os discentes.

Enfim, ao apontarem essas situações como as de significado mais profundo em sua trajetória como estudantes, eles nos parecem revelar que são as relações mais informais ou menos acadêmicas, as atividades mergulhadas de vivências prazerosas e de práticas que proporcionam o desenvolvimento da autoestima.

Nessa direção, as vivências carregadas de forte teor afetivo e marcadas por relações mais coletivas seriam julgadas como centrais na organização da sua intervenção pedagógica na escola. Essa constatação pode ser reafirmada pelo relato do Prof. Mauro, quando ele revela que as atividades esportivas - de jogos e brincadeiras - constituíram-se em um espaço-tempo de conquista de reconhecimento pelos colegas da escola:

A projeção que eu tinha, até por conta do men físico, da minha constituição física maior, eu sempre tive uma constituição física grande para a minha faixa etária, vamos colocar assim, muito proeminente, era a performance nas brincadeiras, qualquer que fossem, isso me agradava muito, como adolescente, principalmente de $1^{a}$ a $4^{a}$ série, aquilo me destacava em relação ao grupo. A queimada que a gente brincava muito na época, a gente brincava muito de rouba-bandeira, eu era muito veloz, muito rápido, muito forte, tanto que isso era em relação a toda a minha turma, isso era muito gostoso porque o adolescente tinha, não sei, ainda continua tendo, essa necessidade de ter para si, chamar muito a atenção, isso era muito legal, isso era uma coisa muito interessante para mim. (Prof. Mauro)

Esse mesmo docente revela que, na vida escolar, nas atividades de "conteúdos", ele não obtinha tanto sucesso. As lembranças da relação com as disciplinas ditas de maior "conteúdo" foram tomadas por ele como as mais negativas desse período de sua formação. 
"Negativa era a relação com o conteúdo, principalmente matemático, com os professores de $1^{\mathrm{a}}$ a $4^{\mathrm{a}}$ principalmente, eu sempre tive um problema com isso. Superei na Química, voltei a ter problema no $1^{\circ}$ ano de Escola Técnica, mas a experiência negativa foi essa" (Prof. Mauro).

Pode-se perceber que esse docente, ao se referir às outras disciplinas da escola (matemática, química, etc.) como dotadas de "conteúdos", deixa transparecer uma primeira representação acerca da EF em relação às demais. Podemos intuir desse relato dois fatos: ou que a EF não teria "conteúdos" ou que seus "conteúdos" seriam diferentes dos das demais disciplinas. Melhor dizendo, a intervenção pedagógica destinada à EF na escola não estaria reduzida a mero ensino dos saberes de referência do seu campo disciplinar. O Prof. Mauro aponta-nos o fato de que os conteúdos pedagógicos da EF estariam destinados a outro tipo de intervenção educativa ou que nela se consubstanciaria outro tipo de aprendizagem, outra ordem de saberes.

Os apontamentos operados pelo Prof. Mauro são ratificados pelo Prof. Leandro, quando este revela que uma de suas experiências mais positivas, durante o período formativo no ensino fundamental, foi a estabelecida com a EF. O sentimento agradável em relação a esse momento educativo se explica, segundo ele, pelo extremo rigor disciplinar do estabelecimento no qual estudava:

Então eu me amarrava na aula desse professor de EF. Eu adorava. Por ser uma
escola pequena e coisa e tal, o regime era duro. Uma escola pequena, poucos alunos,
então o diretor da escola, nossa Senhora, tinha a marcação, sabe, e na aula dele com
toda questão, não é militarista, militar mesmo, a gente ainda tinha mais espaço de
estar ao ar livre e tal, ele jogava com a gente, era ruim de bola pra caramba. Ele
facilitava a relação com os colegas, dos torneios que ele fazia, das interfaces. Nossa
Senhora! Pra mim era muito bom. Em relação à duręa da escola, esse era um espaço
legal que a gente tinha. (Prof. Leandro)

Nessa mesma linha, ao ser questionado ainda sobre o que ficou de mais importante dessas experiências na escola e com a Educação Física, esse docente vai-nos ressaltar que a EF era promotora de um tipo diferenciado de aprendizado, mesmo reconhecendo a própria rigidez do professor dessa disciplina.

Não se fala aqui de conteúdos da EF ou do tipo de didática utilizada pelo seu professor. Ressalta-se a abertura para experiências educativas diferentes do que era corrente nas demais disciplinas da escola ou na vida institucional como um todo. Poder atuar ao ar livre e estabelecer outro tipo de relação com os colegas por si sós parecem ser situações definidoras do que seria, para esse professor, a especificidade do contexto educativo da EF. Esta é vista pelo 
Prof. Leandro como um tipo de "oásis" dentro do "deserto" da vida institucional, contrariando o que parecia prevalecer, isto é, a rigidez disciplinar, a padronização de comportamentos e o racionalismo exagerado dos processos de aprendizagem.

Além de tomar essa disciplina escolar como algo parecido com um "oásis" em contraste com o "deserto" da rigidez e do controle disciplinar, impostos pela ordem institucional, o Prof. Leandro revela que a proximidade manifestada pelo seu professor de EF, que jogava futebol com ele e os colegas durante as aulas, seria também uma constatação das características peculiares do ambiente pedagógico da EF na escola.

$\mathrm{O}$ menor distanciamento físico entre os alunos e o professor e a diluição de escalas hierárquicas e de poder definidas pela lógica escolarizada parecem ser para esse docente mais um elemento definidor, não somente das peculiaridades do espaço educativo da EF, mas também descritor da forma como esses docentes devem portar-se diante dos seus alunos. Ao relatar que seu professor, em alguns momentos, "jogava bola com a gente", nosso informante nos chama a atenção para a importância de uma relação afetiva maior entre professor e alunos.

O Prof. Leandro explicita com mais clareza, no próximo relato, que sua experiência com a EF escolar, ainda como aluno, contribuiu para reforçar um conjunto de crenças e disposições, que parece ser perpetuado pela sua prática docente na escola. De acordo com seu relato, caberia à EF e a ele, como professor dessa disciplina escolar, possibilitar a produção de um ambiente educativo rico de vivências mais formativas, e que a proximidade afetiva entre alunos e professor se constituiria em uma das tônicas centrais do seu trabalho docente.

Olha, eu posso dizer o seguinte, o que de bom eu tenho passado aos meus alunos, muita coisa ainda, até de repente inconsciente, mas, se for parar para pensar, tem muita coisa que está presente. A questão da relação mais aberta, da troca, entendeu? Da abertura num contexto até mais amplo mesmo, em todos os sentidos, então isso pra mim foi o que ficou na época. (Prof. Leandro)

Nesses relatos, podemos ver ressaltados que o longo contato com o ambiente de ensino da EF, ainda na educação básica, contribuiu para a constituição de uma certeza profissional: a aula de EF tem como característica central ser uma disciplina que possibilitaria maiores chances para vivências afetivas mais intensas e para intervenções pedagógicas menos formais. Ressaltaram-se a especificidade do ambiente físico onde a aula se desenrolava, a abertura à expressão mais livre dos alunos, a possibilidade de materialização de experiências grupais e um contato menos formal entre professores e alunos. 
Como salienta esse professor, nessas aulas era possível vivenciar "outros tipos de interface e uma abertura mais ampla, em todos os sentidos".

Em outra perspectiva de análise, podemos perceber que os professores Mauro e Leandro, ao relatarem a positividade de suas experiências com a EF, fazem-no de forma a estabelecer uma relação binária ou de contradição entre o que se vivencia na EF e o que se experimenta nas outras disciplinas e/ou o que seria corrente na ordem institucional da escola. Ou seja, numa lógica institucional na qual se privilegiaria o conteudismo das práticas de ensino - a rigidez disciplinar, a formalidade das relações, a ênfase cognitivista do ensino, o individualismo dos processos de aprendizagem -, caberia à EF oferecer o contrário de tudo isso. Como ainda relata o Prof. Leandro, "em relação à dureza da escola, era o espaço legal que a gente tinha".

Podemos concluir que parte das representações pedagógicas relativas ao papel da EF e de seus professores, construídas ainda no período da formação escolar, deve ser analisada por meio de investigações que procurem mostrar as finas relações entre a força estandardizadora da forma escolar ${ }^{9}$ e o trabalho dos professores dentro da sala de aula. Dá-nos a impressão de haver identificação e incorporação de nossos informantes às práticas e às rotinas institucionalizadas produzidas pela vida escolar. Os professores parecem naturalizar algo que é eminentemente social e, portanto, relacional. Sua função na escola (da EF e de seus professores) seria a de colaborar para o equilíbrio da vida institucional por meio de experiências de ensino que favoreceriam vivências potentes no plano das relações intersubjetivas (aluno-aluno e professor aluno) e da promoção de um ensino centrado na transmissão/incorporação de saberes de ordem comportamental. O relato seguinte proferido pelo professor Mauro aponta nessa direção:

\footnotetext{
Eu estava na $5^{a}$ série, com 11 anos mais ou menos. Eu estava na quadra, assistindo aos meninos faz̧endo um treinamento, quando a bola veio em minha direção, e ele pediu para en jogá-la de volta. Aí ele me chamon para en fazer parte da equipe. A partir dai, a aula que eu nunca perdia era a de Educação Física. Foi sempre um desejo muito grande. Quando eu estava com 13 anos, o Aloisio montou uma escolinha, que era um projeto de extensão da Universidade, e a partir dai eu vim jogando voleibol e até hoje eu ainda gosto muito. Então a história da área de Educação Física veio daí. Não só do jogo em si, mas primordialmente da postura do professor. Desse professor. A forma com que ele lidava com as questões, que eu como adolescente via como um obstáculo, ele as tratava de uma forma muito natural. A obediência, a sexualidade, a relação com o próximo. Uma formação mais ampla, ele via num contexto de pessoa. Ele nunca, eu não me lembro em nenbum momento de alguma orientação descontextualizada da formação bumana. Era o pai fora de casa. (Prof. Mauro)
} 
Atrelado ao destaque dados pelos professores às experiências não formais no interior da escola nos chamou a atenção o fato de que, esses mesmos professores, ao retomarem as memórias de suas experiências escolares mais significativas, o fazem remetendo-se mais fortemente a fatos vividos no ensino fundamental e em seu período mais inicial. Se formos até a bibliografia que versa sobre a origem e as especificidades de cada nível de ensino, verificamos que o Ensino Fundamental tem como uma de suas características mais específicas a maior abertura para relações afetivas e emocionais entre professores e alunos, em contraponto ao nível secundário, criado para preparar as elites para tarefas mais nobres (CHERVEL, 1990). Essas diferenças entre os níveis de ensino acabam por produzir uma série de hierarquizações: a cultura "rudimentar", maternal, feminina, impregnada da dimensão afetiva para o ensino fundamental, e a cultura humanista, racional, individualista e conteudista para o secundário; a cultura material ou a cultura do trabalho manual para o primeiro nível; a cultura intelectual ou a cultura do espírito para o secundário.

Tais divisões ajudariam a definir a identidade dos docentes segundo as ordens de ensino. Mas elas têm também um impacto sobre a tarefa de ensino, sobre suas finalidades, sobre a importância dada às disciplinas escolares e às necessidades dos alunos. Ainda hoje o ensino fundamental é mais identificado com os aspectos da formação integral, centrado mais nas necessidades dos alunos e na dimensão afetiva. Enquanto isso, o ensino secundário ainda guarda a imagem mais intelectualizada, baseada na importância da formação disciplinar e na aprendizagem verbo-intelectual (PETITAT, 1994; LESSARD; TARDIF, 2003)..$^{10}$

Tomando como base o que aponta a bibliografia que versa sobre os estudos biográficos de professores, de como as experiências escolares, ou seja, as experiências desses como alunos contribuem para modelar parte da identidade pessoal e profissional dos docentes, podemos inferir que a seleção de seus relatos, situados quase que exclusivamente dentro do universo do Ensino Fundamental, pode ter relação com as representações pedagógicas por eles construídas acerca de suas habilidades docentes e de suas práticas profissionais na escola. Ao situarem as lembranças mais significativas no espaço-tempo do Ensino Fundamental, esses professores colocam em destaque experiências formativas que apontariam para uma continuidade entre o conhecimento profissional e as experiências pré-profissionais. Tal continuidade parece estruturar um tipo de relação com os sujeitos (em especial os alunos) que daria sentido ao agir pedagógico em EF. 
Essas experiências escolares poderiam ser vistas como referências de modelos de ação ou de representações elaboradas e veiculadas pelos professores de EF a respeito da natureza de sua prática: EF vista como uma das disciplinas escolares "talhadas" a intervir de forma mais direta nos processos de educabilidade humana.

Em função desses papéis atribuídos à EF, os seus professores, ao selecionar suas experiências escolares mais significativas, extraem aquelas que ainda são organizadoras e definidoras de suas competências pedagógicas na escola, quais sejam: ser capaz de interferir na formação humana dos alunos, saber ensinar em meio a experiências de gratuidade e prazer, ser mais afetivo com os alunos e ainda saber ensinar com a predominância de experiências e atividades grupais. Ao falarem sobre o que seria a marca de sua intervenção pedagógica na escola, os professores Mauro e Leandro acabam por delinear um perfil de ação mais voltado aos aspectos mais educativos do que instrutivos:

É quase como se fossem meus filhos. Eu não consigo estar lidando com eles como pessoas por ser minha obrigação como profissional, eu não consigo lidar com eles dessa forma e esquecê-los. Hoje eu fiz aquilo e deixei para lá. Não é paternalismo, mas é de responsabilidade, tanto quanto teria o pai nesse processo, por conta da minha visão de mundo, da minha expectativa de vida, de uma percepscão social, violência e uma série de outras coisas, o interesse, o quanto me faz bem do ponto de vista pessoal a minha relação com a escola, o meu trabalho, o quanto eles podem se dar bem também com isso de tratar os outros com respeito, com carinho, com educação, de ser gentis, saber agradecer, saber pedir licença, abrir uma porta. Não estou dizendo que os pais não façam isso, quem sou eu para dizer isso. Nem seria leviano dizer isso. Mas é isso que eu acho que a gente pode estar ajudando, porque o tempo escolar de permanência na instituição é muito grande. Nesse contexto todo, só consigo concebê-los como filhos mesmo, com essa responsabilidade nessa construcão. Eu acredito que a disciplina Educação Física no contexto escolar seja uma das disciplinas que mais podem e mais colaboram com esse tipo de atividade. O perfil que o mercado de trabalho exige hoje das pessoas está muito envolvido com o trabalho em grupo. Acho que esse é o momento de construção, de ajuda nesse sentido. Outro, do estreitamento das relações deles mesmos, de conviver com o diferente, de conviver com idéia diferente, de respeitar essa idéia diferente, que querer ser compreendido porque a gente sempre quer, mas de compreender as ações e de respeitar essas ações, o trabalho em grupo dá muito essa possibilidade, que eu acho riquíssima nessa parte. Há uma frase que resume tudo isso, que é da Marisa Monte, numa música que ela dá nome de gentileza; ela dir o seguinte: vale mais o livro ou a sabedoria? Eu não tenho dúvida de que é a sabedoria, e entendo que a Educação Física nesse contexto contribui muito e mais do que qualquer outra nesse contexto, não tenho dívida disso. (Prof. Mauro)

De que a vida, o dia-a-dia da gente é feito numa questão de limites, de respeito, de saber ouvir e abstrair. A questão do relacionamento, a questão da afetividade é bem aberta, a proximidade das relações; eu não abro mão disso, de jeito nenhum. (Prof. Leandro) 
Sobre os conteúdos presentes nas falas dos sujeitos, vale citar o estudo de Raymond (2000), que, ao trabalhar no curso de formação de novos professores com alunos oriundos dos diversos campos disciplinares, percebeu que eles se dirigiam uns aos outros quase sempre fazendo alusões às disciplinas em que cada um ia especializarse. Sendo assim, os alunos das áreas de Ciências Exatas eram vistos ou se apresentavam como rigorosos, mais rígidos e metódicos e que deixavam pouco espaço para interpretação; por sua vez, aqueles das disciplinas literárias e de Ciências Humanas eram vistos como pouco sólidos, ligados aos contextos, e seus saberes recebiam um estatuto inferior ao dos demais campos disciplinares. Para Raymond (2000), a força e a certeza em que essa percepção era expressa mostravam-se inversamente proporcionais a seu grau de refinamento. Segundo ela, essa percepção está ligada a diversas manifestações da forma escolar, como os manuais, os exames, os controles, os métodos de ensino que acompanham a aprendizagem das noções em cada matéria de ensino. Assim, as ideias construídas em relação aos professores dos diversos campos disciplinares pouco representam os saberes disciplinares.

Em todos os dois relatos, vai ficando claro que a experiência escolar se constituiu em uma referência orientadora da constituição de atitudes, crenças e representações pedagógicas do que seria o papel da EF na escola, do perfil das habilidades pedagógicas particulares de seus professores, da especificidade de sua intervenção pedagógica, como também em relação ao papel dessa disciplina escolar dentro da vida institucional. Esses docentes, ao selecionarem determinados fatos de sua socialização escolar, fazem-no na tentativa de objetivar a especificidade de seu estilo de ensino, utilizando referenciais espaçotemporais que consideram válidos para alicerçar a legitimidade das certezas experienciais que reivindicam (TARDIF; RAYMOND, 2000).

Ainda sob essa mesma perspectiva, constatamos que $O$ processo de aproximação e definição seria, para esses docentes, o campo de atuação pedagógica da EF na escola, que foi fortemente marcado por professores de EF situados (à época) no ensino fundamental. Para os professores Mauro e Leandro, essa influência foi tão forte que acabou por interferir na escolha da profissão. Em ambos os depoimentos, os docentes dessa disciplina aparecem como modelos de atuação docente, como referências fundantes de como se comportar e atuar profissionalmente com o ensino da EF, com a sua função pedagógica específica e com o seu papel dentro da vida escolar. Enfim, são personagens dessa trajetória que contribuíram de maneira significativa para a edificação de modelos de atuação pedagógica 
em EF. Essa afirmação pode ser constatada nos relatos dos nossos sujeitos de pesquisa, quando questionados sobre os motivos que os levaram a optar pela graduação em EF. Eis um relato:

\begin{abstract}
Eu estava na $5^{a}$ série, com 11 anos mais ou menos. Eu estava na quadra, assistindo aos meninos fazendo um treinamento, quando a bola veio em minha direção, e ele pediu para eu jogá-la de volta. Ai ele me chamon para en fazer parte da equipe. A partir dai, a aula que eu nunca perdia era a de Educação Física. Foi sempre um desejo muito grande. Quando eu estava com 13 anos, o Aloísio montou uma escolinha, que era um projeto de extensão da Universidade, e a partir dai eu vim jogando voleibol e até hoje eu ainda gosto muito. Então a história da área de Educação Física veio daí. Não só do jogo em si, mas primordialmente da postura do professor. Desse professor. A forma com que ele lidava com as questões, que eu como adolescente via como um obstáculo, ele as tratava de uma forma muito natural. A obediência, a sexualidade, a relação com o próximo. Uma formação mais ampla, ele via num contexto de pessoa. Ele nunca, eu não me lembro em nenhum momento de alguma orientação descontextualizada da formação humana. Era o pai fora de casa. E era uma pessoa amiga demais, de ligar para casa e saber se a gente estava machucado, se estava bem; de um dia estar fazendo o treino furioso, com raiva, não dando conta de nada, e, no dia seguinte, no treino, perguntava se estava tudo bem, como é que tinha ido. Explicava porque aquilo acontecia. Acho que isso foi fundamentou minha decisão e ela vai ser contínua. (Prof. Mauro)
\end{abstract}

Nota-se a intensidade da relação afetiva estabelecida pelo Prof. Mauro, no ensino fundamental, com o seu professor de EF e também treinador de voleibol. Ao frisar que as intervenções mais significativas desse professor-modelo aconteceram em função da sua capacidade de intervir na sua formação humana, ou seja, na modulação de seu comportamento, de suas atitudes e afetos, esse docente revela-nos quais seriam as habilidades geradoras de certezas de sua capacidade de ensinar e de sua performance pedagógica como professor de EF. É interessante percebermos que esse professor expressa um quadro hierárquico do valor simbólico dessas experiências na medida em que coloca em primeiro plano aspectos de uma intervenção pedagógica mais diretamente a aprendizagens de ordem comportamental, comparativamente com fatos ou exemplos sobre a capacidade desse professor em saber ensinar o conhecimento específico da EF. São deixados de lado, portanto, os aspectos da instrução e ressaltadas as dimensões formativas mais amplas. O relato a seguir vai reforçar essa constatação:

Eu nunca deixei de considerar as situações da minha condição humana como o Aloísio me passava, naquilo que eu fazia com os meus alunos, e sempre, a partir daí, logrei muito sucesso como profissional. Contextualizando com a situação de vida, de estar podendo somar, não moldar, mas somar situacões de vida, de caráter mesmo, de entender que não precisa estar xingando o outro, que não precisa estar desfazendo 
do outro, que não precisa ser agressivo com o outro para conseguir aquilo que você desejava e tal. De maneira a ajudar os alunos de uma forma mais ampla do que aquela da aula em si. (Prof. Mauro)

Da mesma forma que Mauro, Leandro também vai destacar o professor de EF do ensino fundamental como central na sua opção por esse mesmo curso. Vejamos:

O que me influencion a fazer a EF foi outro professor de Educação Física em que eu me espelhei muito. Eu tive aula com ele no ensino fundamental. E, por incrivel que possa parecer, ele era militar, um sargento do Exército, formado na Escola de Educação Física do Exército. E en gostava daquela doideira dele, gostava, aí malhava, vai lá, era um regime de caserna mesmo, barra pesada, então eu me espelhei muito nele. Independentemente de tudo, eu tinha prazer de estar ali com ele. Poxa, eu, às vezes, engasgo. Ele jogava com a gente, era ruim de bola pra caramba. Ele proporcionava a relação com os colegas, os torneios que ele fazia, das interfaces. Essa relação fez. com que ele fosse um grande marco, e eu te falo, tive outros professores como referência, mas esse foi assim. Nossa Senhora! Dentro do que ele se propunha, ele era muito bom. Eu confesso que eu tentei copiá-lo e, nos meus primeiros momentos, não tenho vergonba nenhuma de falar; nos meus primeiros anos, eu me espelhava muito nele. (Prof. Leandro)

O Prof. Leandro nos mostra que o docente dessa disciplina foi uma referência organizadora para sua função pedagógica dentro da escola. Em sua narrativa, são destacadas algumas qualidades do professor, como aquele que possibilitava uma relação mais informal com os colegas, um contato professor-aluno diferenciado e que proporcionava, por meio de torneios esportivos, vivências formativas experienciadas quando um trabalho mais coletivo se materializava. Essas atividades seriam as que Leandro denomina de outras interfaces.

Mais uma vez, é destacado um conjunto de representações pedagógicas relativas às práticas profissionais típicas dos professores de $\mathrm{EF}$ e do momento específico da aula dessa disciplina. Entre esses saberes pedagógicos, é sublinhada a capacidade do professor de trabalhar em grupo, de promover práticas de ensino mais coletivas e de saber ensinar com forte teor afetivo, que, em vez de obstaculizar o ensino, se tornariam elementos diferenciadores da prática profissional desses docentes.

Quando indagado sobre o que ainda permanece em sua prática profissional da relação estabelecida com esse professor de EF, ele chama a atenção para o fato de que a EF se constitui em um espaço-tempo de maior potência para a expressão de vivências afetivas e relacionais dentro da escola. O Prof. Leandro foi enfático ao responder tal questionamento: "é esse espaço da relação. É esse espaço, eu acredito muito nisso. Com toda a certeza. Com toda a certeza". 
Em relação a essa questão, vale aqui citar a observação feita por Fontoura (1995) sobre a lógica que rege as situações educativas dentro da escola. Segundo ela, a ação educativa encerra dois planos: o da realidade observável, do explícito, do racional e do subjetivo, do implícito, do afetivo. No entanto, na vida escolar, como geralmente nas atividades socioprofissionais ou políticas, a afetividade aparece, na maioria das vezes, como obstáculo. Nos relatos analisados aqui neste trabalho, o elemento da afetividade não é apresentado como um dificultador da prática educativa. Essa centralidade, ao contrário, aparece no discurso dos nossos professores como referência geradora de certezas particulares sobre a própria capacidade de ensinar.

Algo de comum parece emergir dos relatos dos dois professores: o fato de que todos encontram na EF a possibilidade de operar uma intervenção pedagógica dotada de singularidades que os diferenciariam dos demais professores da escola. Tais ações educativas exigiriam deles o aguçamento da sensibilidade para a observação de determinadas dimensões da subjetividade dos alunos. Está embutida nessa observação que o foco específico de sua intervenção profissional direcionar-se-ia, assim como com os docentes Mauro e Leandro, no sentido de serem capazes de perceber e intervir na forma como seus alunos se comportam na modelação de seus valores e na maneira como conduzem suas relações coletivas.

\section{CONSIDERACְÕES FINAIS}

No que tange aos resultados da nossa investigação, pudemos concluir, primeiramente, que a trajetória pré-profissional de nossos informantes, sobretudo quando a sua socialização escolar, foi significativa para produzir um conjunto de crenças e representações pedagógicas relativas ao papel a ser cumprido pela EF e pelos seus professores no interior da escola. São certezas sobre a profissão docente em Educação Física edificadas fora da experiência do ensino, transformadas e integradas à sua identidade profissional ou às suas práticas profissionais.

Um primeiro traço indica que o ensino dos conteúdos da EF estaria mais a serviço de dimensões formadoras do que de dimensões "ensinantes". Os professores parecem aprender desde cedo que os conteúdos de EF devem ser pensados e selecionados em função dos educandos, de sua formação, de sua educação, apontando horizontes, intencionalidades e significados mais abertos. Garantir essas aprendizagens é a finalidade primeira. Os conteúdos mais fechados 
são inseparáveis dos conhecimentos e das competências humanas mais abertas. A docência, a escolha de conteúdos ou o programa da disciplina parecem ser inseparáveis das tensões entre dimensões a formar, protótipos de seres humanos a desenvolver.

Já o segundo traço diz respeito à naturalização de determinados papéis escolares destinados à EF, por força dos mecanismos reguladores do caráter escolar. Caberia à EF, entre outras funções, o papel de oferecer aos alunos um espaço de vivências mais espontâneas, livres, gratuitas, prazerosas e de forte teor educativo. Essa percepção dos professores parece surgir em função da experiência que tiveram como alunos num contexto institucional marcado pela formalidade das relações, pelo conteudismo das práticas de ensino e pela rigidez disciplinar. É como se, nas outras disciplinas da escola, fosse quase impossível vivenciar com a mesma intensidade as experiências educativas que seriam próprias da EF.

Assim, podemos constatar que parte importante de seus saberes, sensibilidades, crenças e disposições profissionais não podem ser reduzidas às suas experiências com o ensino propriamente dito da EF. É possível intuir que aspectos da compreensão dos professores pesquisados acerca do papel da EF na escola têm vinculação direta com as delicadas relações existentes entre as formas de regulação social da escola, sua organização curricular, suas relações de poder e a lógica própria do ensino dessa disciplina. Salienta-se aqui, portanto, a força da experiência escolar em geral e não somente com a EF.

Nos relatos, fica evidente que o legado da socialização escolar permanece mais ou menos estável sob a forma de valores acerca do ensino, das escolhas dos conteúdos a ensinar, das estratégias pedagógicas, da percepção das necessidades dos alunos em relação ao conteúdo a ser ensinado, da compreensão com referência ao papel da EF pelo estabelecimento de ensino e do entendimento no tocante às diferenças entre a EF e as demais disciplinas. Nossos depoentes parecem alimentar a crença de que seria próprio da EF oferecer aos alunos vivências de integração, de relações interpessoais, de gratuidade e de fruição, além de formação de valores e comportamento. Fica mais ou menos evidenciado que o legado da socialização escolar parece ter sido fundamental para que os professores perpetuassem a compreensão de que também seria específico da EF propiciar aos discentes intervenções pedagógicas voltadas mais diretamente para a educação do que para a instrução. Podemos dizer que a socialização escolar tem peso importante no processo de constituição do que poderíamos chamar de um estilo de ensino em que a dimensão da educabilidade humana ganharia maior atenção e reconhecimento por parte dos professores. 
Todavia, essas certezas relativas demonstradas pelos nossos depoentes a respeito do que seria o papel da EF e de seus professores são inversamente proporcionais ao seu grau de refinamento reflexivo. Pudemos perceber que a crença alimentada por eles de limitar ou priorizar a função da EF à educação geral (socialização) dos alunos é no mínimo questionável. Os professores das demais disciplinas não teriam também essa função? Não seriam atribuições centrais dos professores de Educação Física a sistematização e a transmissão de um conhecimento que é específico dessa disciplina escolar? Tais questões nos provocam a pensar o papel do currículo escolar no processo de constituição de subjetividades e identidades. O currículo escolar ensina a um aluno quem ele é e isso se realiza, muitas vezes, à custa da exclusão de outras identidades possíveis. A experiência escolar desses professores parece ter produzido forte identificação com um modelo profissional que, se não exclui a imagem consagrada do professor ensinante (que tem como uma das suas funções centrais na escola a transmissão de uma esfera da cultura), a coloca numa posição desigual ou em desconexão com o papel socializador e educativo próprio da identidade profissional dos professores.

O que nos parece ser importante realçaré que essas representações e certezas relativas aos papéis pedagógicos a ser cumpridos pela EF são produzidas muito em razão do contato dos docentes com uma escola que existe para além da sala de aula. Não há como desvincular as representações pedagógicas construídas pelos professores com relação aos papéis da EF sem relacionarmos esses ao cotidiano da escola, dos tempos escolares, da organização dos espaços e ambientes da escola. Essa escola dentro de outra escola contribui para estruturar as certezas sobre a própria prática docente.

Pensar a formação de professores na escola em relação ao estabelecimento de ensino pode ajudar a equacionar a tradicional dicotomia entre o fenômeno de socialização e o de escolarização. Permite outra "visibilidade" da dimensão formativa dos contextos educacionais e das situações de trabalho, abrindo caminho à reconsideração e ao enriquecimento dos estudos sobre a formação "centrada na escola", encarando o funcionamento organizacional como um jogo conflituoso entre atores sociais que participam, de forma permanente, de um processo coletivo de aprendizagem. Ao tomarmos o estabelecimento de ensino como um contexto "globalmente formativo" para o conjunto dos seus habitantes, poderíamos abrir caminho, por meio de estudos empíricos, para superar teoricamente a dissociação tendencial entre a educação de 
crianças e jovens e a educação de adultos. O processo de formação de adultos (professores) e jovens (alunos) aparece, assim, referido a um mesmo espaço organizacional, a um mesmo tempo e aos mesmos princípios (CANÁRIO, 1996).

Esses achados da nossa pesquisa nos levam a refletir também sobre maneiras e estratégias de formação continuada em serviço que ainda insistem em colocar como centrais questões restritas aos conteúdos de ensino, às metodologias de transmissão das disciplinas escolares, entre outras facetas que visam atacar problemas relacionados com a transmissão do conhecimento. Não desfazendo totalmente dessas iniciativas, entendemos que elas devam ser complementadas com discussões que foquem o reordenamento das relações de poder dentro da escola, da compartimentalização do conhecimento e da construção de uma atitude mais colegiada por parte dos professores, na qual o individualismo pedagógico possa dar lugar ao diálogo e ao debate mais solidário das experiências de ensino construídas pelos professores de cada uma das disciplinas escolares.

Tal reflexão vale também para a formação profissional ("inicial”) na Universidade. Se entendermos que o legado da socialização escolar pode permanecer forte e estável através do tempo e, por consequência, influenciar o tipo de investimento que os alunos farão no decorrer de sua trajetória formativa no curso de licenciatura, há que se investir em ações de formação que contribuam para modificar determinadas crenças e certezas que os estudantes trazem a respeito do ensino e da prática docente em Educação Física. Para além de uma formação marcada pela lógica disciplinar que, na maioria das vezes, lhes fornece somente um conjunto de conhecimentos proposicionais e informações, deve-se executar um trabalho profundo sobre os filtros cognitivos, sociais e afetivos através dos quais os professores de EF processam as experiências vividas durante sua trajetória como estudantes na Educação Básica. Caso contrário, corremos o risco da formação para o magistério ter um impacto pequeno sobre o que pensam, creem e sentem os alunos dos cursos de licenciatura em EF, antes de esses começarem a atuar prfissionalmente na escola.

\section{REFERÊNCIAS}

ARROYO, M. G. Ofício de mestre: imagens e autoimagens. Petrópolis: Vozes, 2000.

BORGES, C. M. F. O professor de Educação Física e a construção do saber. Campinas: Papirus, 1998. CANÁRIO, R. O estudo sobre a escola: problemas e perspectivas. In: BARROSO, J, (Org.). O estudo da escola. Porto: Porto Editora, 1996. 
CATANI, D. B. Práticas de formação e ofício docente. In: BUENO, B et al. (Orgs.). Vida e o ofício de professores. São Paulo: Escrituras Editora, 1998. p. 23-31.

CHERVEL, A. História das disciplinas escolares: reflexões sobre um campo de pesquisa. In: Educasão e Realidade, Porto Alegre, n. 2, p. 177-229, 1990.

FIGUEIREDO, Z. C. C.. A formação docente, currículo e saber. In: CAPARROZ, F. E. (Org.). Educação Física escolar: política, investigação e intervenção. v. 1. Vitória: Proteoria, 2001. p. 115- 139.

FONTOURA, M. M. Fico ou vou-me embora? In: PORTUGAL, A. N. (Org.). Vida de professores. Porto, Porto Editora, 1995. p. 171-198.

GOODSON, I. F. Dar voz ao professor: as histórias de vida dos professores e o seu desenvolvimento profissional. In: NÓVOA, A. (Org.). Vida de professores. Porto: Porto Editora, 1995. p. 63-78.

HOLLY, M. L. Investigando a vida profissional dos professores: diários biográficos. In: NÓVOA, A. (Org.). Vida de professores. Porto: Porto Editora, 1995. p. 79-110.

HUBERMAN, M. O ciclo de vida profissional dos professores. In: NÓVOA, A. (Org.). Vida de professores. Porto: Porto Editora, 1995. p. 31-62.

JULIA, D. A cultura escolar como objeto histórico. Revista Brasileira de História da Educação, n. 1. jan./jun. 2001.

LESSARD, C.; TARDIF, M.. Les identities enseignantes: analyse de facteurs de différenciation du corps enseignant québécois 1960-1990. Montreal: Editions du CRP, Université de Sherbrooke, 2003.

MOITA, M. C. Percursos de formação e de trans-formação. In: NÓVOA, A. (Org.). Vida de professores. Porto: Porto Editora, 1995. p. 111-140.

MORENO, A. Educação Física: de que profissão e de que profissional se fala? In: FRANCO, C.; KRAMER, S. (Orgs.). Pesquisa e educação: história, escola e formação de professores. Rio de Janeiro: Ravil, 1997. p 257-275

NÓVOA, A. (Org.). Os professores e sua formação. Lisboa: Dom Quixote,1995.

OLIVEIRA, W. F. Narrativa e saberes docentes. In: (Org.). Narrativas e saberes docentes. Ijuí: Ed. UNIJUÍ, 2006. p. 169-190.

PETITAT, A. Produção da escola/produção da sociedade: análise sócio-histórica de alguns momentos decisivos da evolução escolar no ocidente. Porto Alegre: Artes Médicas, 1994.

RAYMOND, D. L'utlisation d'aproches biographiques em formation à l'enseignement. Conférence présentée á la Pontifícia Universidade Católica do Rio de Janeiro. Rio de Janeiro, 2000. Mimeografado.

RAYMOND, D. et al. Savoirs préprofessionnels et formation fondamentale des enseignantes et des enseignants: approche autobiographique. In: GAUTHIER, C. et al. (Dir.). Le savoir des ensignants: Que savent-ils? Montreal: Éditions Logiques, 1993. p. 137-168.

SACHOT, M. La formation professionnelle à l'enseignement entre deux vecteus integrateus en conflit: les disciplines et le curriculum. Revue Educacion et francophonie. Montreal, v. 28, n. 2, automne-hiver, 2000. Revue Virtuelle. Disponível em: <http://www.acelf.ca/revue>. Acesso em: 30 mar. 2003.

TARDIF, M.; RAYMOND, D. Saberes, tempo e aprendizagem do trabalho no magistério. Educ. Soc., Campinas, v. 21. n. 73. dez. 2000.

TARDIF, M. Saberes docentes e formação profissional. Petrópolis: Vozes, 2002. 


\section{NOTAS}

${ }^{1}$ Este artigo é uma síntese de minha tese de doutorado defendida no Programa de PósGraduação em Educação da PUC-Rio.

${ }^{2}$ Esta pesquisa contou com o apoio financeiro da CAPES.

${ }^{3}$ No estudo lançamos mão do modelo tipológico para identificar e classificar os saberes dos professores criados por Tardif (2002). Nesse modelo as vivências de formação préprofissionais seriam aquelas que os docentes vivenciam antes da entrada em instituições de formação para o magistério. Esses ambientes e tempos de formação seriam a família, o ambiente da vida, a educação no sentido lato, a escolarização primária e a secundária.

${ }^{4}$ Os modelos de ação são as representações elaboradas e veiculadas pelos professores a respeito da natureza de sua prática, representações essas que servem para defini-la, estruturála e orientá-la em situações de ação (TARDIF, 2002).

${ }^{5}$ Sobre o peso da experiência esportiva e/ou com as práticas corporais, vividas anteriormente ao início da trajetória de formação profissional dos professores de EF, ver os estudos de Moreno (1997), Borges (1998) e Figueiredo (2001).

${ }^{6}$ É importante lembrar que os professores são trabalhadores que têm uma relação de imersão muito precoce e longa com o seu ambiente de trabalho. Tais profissionais ficam imersos em seu lugar de trabalho (a escola) durante aproximadamente 15 anos, antes de atuar como docentes.

${ }^{7}$ Todos os procedimentos éticos para a rewalização da pesquisa foram respeitados: reunião com os professores para explicação e discussão sobre os objetivos da pesquisa, dos procedimentos de coleta de dados, autorização dos mesmos para realização da investigação e a garantia de privacidade para aqueles que participassem do desenvolvimento do estudo.

${ }^{8} \mathrm{~A}$ designação dos nomes dos dois sujeitos da nossa pesquisa é fictícia. No intuito preservar sua privacidade, decidimos não utilizar os seus nomes verdadeiros.

${ }^{9}$ Para Julia (2001), a forma escolar caracteriza-se por meio de um conjunto coerente de traços: constituir-se em um universo separado para a infância, a importância das regras na aprendizagem, a organização racional do tempo, a predominância da linguagem escrita, a multiplicação e a repetição de exercícios, cuja função consiste em aprender conforme determinadas regras.

${ }^{10}$ Sobre essa mesma questão, vale a pena citar as considerações de Sachot (2000), quando ele desenvolve argumentações sobre o surgimento e a conceituação do que seja currículo e disciplina. Em uma delas, o autor vai apontar que o conceito de disciplina estaria mais relacionado com o universo do ensino secundário, enquanto o termo currículo estaria mais relacionado com o universo do ensino fundamental. Isso porque, no nível secundário, a preocupação central seria com a educação do intelecto, ou seja, com a instrução, ao passo que, no nível fundamental, a centralidade da intervenção pedagógica estaria mais voltada para a educação mais ampla, isto é, com a formação de condutas, hábitos e atitudes.

Recebido: 02/05/2014

Aprovado: 15/04/2015 
Contato:

Universidade Federal de Minas Gerais - EEFFTO

Av. Pres. Antônio Carlos, 6627 - Pampulha Belo Horizonte $|\mathrm{MG}|$ Brasil

CEP 31.270-901 
